Abstracta Iranica Abstracta Iranica

Revue bibliographique pour le domaine irano-aryen

Volume 28 | 2007

Comptes rendus des publications de 2005

\title{
Wall Paintings and Other Figurative Mural Art in Qajar Iran. Costa Mesa (CA), Mazda Publishers, 2005, 208 p. et 13 ill. n.-b.
}

Eloïse Brac de La Perrière

\section{(2) OpenEdition}

Journals

Édition électronique

URL : http://journals.openedition.org/abstractairanica/11452

DOI : 10.4000/abstractairanica.11452

ISSN : 1961-960X

Éditeur :

CNRS (UMR 7528 Mondes iraniens et indiens), Éditions de l'IFRI

Édition imprimée

Date de publication : 15 mai 2007

ISSN : 0240-8910

Référence électronique

Eloïse Brac de La Perrière, « Wall Paintings and Other Figurative Mural Art in Qajar Iran. Costa Mesa (CA), Mazda Publishers, 2005, 208 p. et 13 ill. n.-b. », Abstracta Iranica [En ligne], Volume 28 | 2007,

document 224, mis en ligne le 18 septembre 2007, consulté le 25 septembre 2020. URL : http:// journals.openedition.org/abstractairanica/11452; DOI : https://doi.org/10.4000/abstractairanica 11452

Ce document a été généré automatiquement le 25 septembre 2020.

Tous droits réservés 


\title{
Wall Paintings and Other Figurative Mural Art in Qajar Iran. Costa Mesa (CA), Mazda Publishers, 2005, 208 p. et 13 ill. n.-b.
}

\author{
Eloïse Brac de La Perrière
}

1 Rétablir l'art qajar dans une perspective historique, économique et sociale, tel est le but fixé d'emblée par Willem Floor dans cet ouvrage portant sur différentes formes de représentations figurées (la peinture principalement) décorant les murs des édifices dans l'Iran des Qajars. C'est en s'appuyant exclusivement sur une approche historicosociale que l'A. tente de répondre aux questions suivantes: quand ont-elles été utilisées? Par qui et dans quels buts? Dans quels édifices et dans quelles villes? Quels en sont les sujets? Comment ces représentations étaient-elles perçues par un large public? Ont-elles entraîné de réels changements? W.F., reprochant aux historiens de l'art d'avoir jusqu'à présent négligé ces questions, exclut pour sa part de son propos toute étude proprement artistique des œuvres. La qualité de l'iconographie illustrant cet ouvrage s'en ressent fortement, les reproductions étant tout à la fois trop peu nombreuses (13 en tout) et de mauvaise qualité.

L'ouvrage, découpé en cinq chapitres, présente toutefois le grand intérêt d'offrir au lecteur un riche inventaire des monuments en rapport avec le sujet. Dans un premier chapitre, W.F. recense de manière très didactique, parfois un peu schématique, les principaux acteurs du sujet - mécènes royaux et artistes -, tout en en définissant la portée générale, tant politique que sociale. Les quatre chapitres qui suivent reprennent brièvement, ville par ville, édifice par édifice, l'ensemble des lieux agrémentés de telles ornementations. L'A. les inventorie de la sorte : d'abord les édifices royaux et demeures privées (chap. 2, pp.43-120), qui constituent la grande majorité des architectures concernées, puis les bâtiments publics, autrement dit les bazars, bains, caravansérails et relais de poste (chap. 3, pp.121-134), puis encore les édifices religieux (chap.4, pp. 134-161), et pour finir les bas-reliefs (chap. 5, pp. 162-190), un décor ne figurant que 
trop rarement dans les études portant sur l'art qajar. L'ouvrage de W.F. présente encore de ce point de vue un intérêt certain.

3 Rejetant vigoureusement, et à juste titre, le postulat selon lequel l'art qajar a trouvé sa plus belle expression dans les laques, la peinture sur toile et les émaux, W.F. se pose ici en détracteur d'un courant de pensée qui connut une certaine postérité en histoire de l'art et qui a certainement contribué, durant un temps, à la méconnaissance du sujet. Toutefois, depuis quelques années déjà, d'importantes études artistiques sur la peinture qajar ont vu le jour et laissent présager d'un regain d'intérêt pour ce qui demeura, pendant trop longtemps, l'un des parents pauvres de l'art persan.

INDEX

Thèmes : 5.1. Monde iranophone

\section{AUTEURS}

ELOÏSE BRAC DE LA PERRIÈRE

Université Paris IV - CNRS - Paris 